\title{
How to Create Safety for Battered Women? \\ Conclusions from Several Decades of Research and Practice in Europe
}

\author{
Silke Birgitta Gahleitner ${ }^{*}$
}

${ }^{1}$ Alice Salomon Hochschule - University of Applied Sciences, Alice-Salomon-Platz 5, D-12627 Berlin, Germany

KEYWORDS

Domestic violence effects

Service users

Service providers

Social support

\begin{abstract}
A two-year project on 'A Comparative Analysis of Community-Focused Initiatives Aimed at Supporting Women, Children and Young People who have been the Focus of Violence, Exploitation or Trafficking in Three Regions of the United Kingdom, Germany and Romania' which was funded by the Daphne programme, was carried out by Newman University College in Birmingham/England together with the Alice Salomon University of Applied Sciences, Berlin/Germany and Lucian Blaga University of Sibiu/Romania. Service users, in particular, and policy-makers and professional helpers were asked about their experiences with the care structures in their respective countries. The results show that even after many decades of providing professional support for women in violent relationships services are still frequently unable to help the victims to find a 'safe place' which could allow them to escape from the violence. The article collates the results of the Daphne project and recent international research on the subject of trauma and domestic violence, reflects on the causes of this gap in care provision and suggests how professional approaches to solving this dilemma could be improved.
\end{abstract}

\section{Introduction}

Daphne, a core anti-violence programme of the European community, has impacted the development of policies by providing incentives for programme development and transnational exchange for different service

\footnotetext{
${ }^{*}$ Contact address: sb@gahleitner.net (S. B. Gahleitner)
} 
providers, particularly non-governmental organisations (NGOs) with the aim of ending violence against women and children. The programme was established in 1997 and focuses on all types of violence against children, young people and women. The main aims have been to support consciousness raising, training and research initiatives, promote cooperation between NGOs, voluntary sector organizations and local public institutions across member states and beyond and to facilitate the exchange of good practices through networking. The activities that it has been funding have been linked to the development of a common set of norms and practices aimed at supporting local policy actors in the search for feasible solutions for enhancing victim services and thus effectively addressing violence against women and children.

Daphne has also a unique role in offering scholarly and practice-based research and information to address the needs of women and children who are being subjected to violence, exploited and trafficked. Daphne's role in the prevention, protection and prosecution of violence against women and children is therefore research-based and critical to the development of policies and initiatives within the European Union and beyond. Along the Daphne III Programme from 2007-2013 the Newman University College in Birmingham England, the Alice Salomon University of Applied Sciences Berlin, Germany and the Lucian Blaga University of Sibiu, Romania in 2009 received a two-year research grant to address violence against women and children. The aim of the project has been to explore support services for persons who have become victims of violence. The target groups were women, adolescents and children having accessed community based support initiatives as victims of abuse, exploitation or trafficking.

One specific objective of the research project was to gain a clearer understanding across partner communities of the ability of victim support services to meet the needs of women who have experienced domestic violence. In order to achieve this, the research provided opportunities for service users to describe their experiences and the quality and relevance of the support made available to them. Participants were asked to consider how current support services could be improved, expanded and restructured through increasing the level of user involvement. One of the main results of this part of the study was that many of the women 
interviewed reported that the safety offered them by the psychosocial care system was not sufficient to allow them to extricate themselves permanently from the violence. This result was particularly significant because both researchers and practictioners in the field of domestic violence are repeatedly confronted with the fact that women who have been battered return to their violent husbands even though help is offered to them.

The following article therefore focuses on the phenomenon of insufficient safety in the system of care for women who are victims of violence and seeks to use the results of the research to establish how services can provide adequate interdisciplinary responses - for both practice and further research - in the anti-violence sector.

\section{Domestic violence - data and facts from Europe}

Gender-based violence is by no means a marginal phenomenon. According to a report by the World Health Organisation (1996) the problem of violence is one of the most widespread health risks in the lives of women and girls (Harvey, Garcia-Moreno and Butchart 2007). For many women violence is therefore still an everyday occurrence - be it in their own homes, in their partner relationships, at the workplace or in the public arena (Rutz 2006). Thus, over half of the women living in Europe have experienced some form of physical, sexual or psychological violence before they are seventeen. Violence against women is still perpetrated mainly by men and frequently by their own partners in the domestic sphere (Schröttle and Müller 2005).

The range of forms and severities of the violence is broad, from boxing the ears and angry shoves to hitting with objects, beating up and the use of weapons. The contexts in which the violence occurs also vary widely, from harassment in the street and boundary violations at the workplace to many different forms of disrespect, maltreatment and sexual abuse in the family and elsewhere, also rape and the killing and trafficking of women in wider arenas. The violence causes substantial direct harm Iin both the short- and the long-term. It impairs victims' personal health and restricts their freedom of movement and sense of security (Gahleitner 2007).

All forms of violence are strongly associated with mental sequelae, including sleep disturbances, anxiety, impaired self-esteem, depression 
ranging from mild depressive states to suicidal ideation, self-harming and eating disorders. There are also clear indications of increased impairment of physical health in women who have experienced physical or sexual violence. Thus, women who are victims of violence significantly more often have headaches, gastrointestinal problems and gynaecological symptoms (Felitti 2002). Addiction among women is also closely associated with experiences of violence: 'Health impairments due to the effects of gender-based violence are thus not only an enormous problem for the victims and their relatives, but also place no small burden on society as a whole, both socially and financially' (Kavemann 2001: 15).

In addition to these health problems, we generally also find social sequelae such as separation from relationship pathe breaking up of partner relationships (in some cases even where the partner was not the perpetrator), moving house and giving up or changing jobs. In the lives of many women, the experience of violence seems to mark break with old relationship and work contexts. This is most frequent after sexual and physical violence, but has also been found to occur surprisingly often following emotional violence. It should be taken into account that roughly half of the women concerned do not talk to anyone about their experiences, that is, they do not get help. When they do confide in someone, this is usually a close girlfriend or family member. Only a small percentage seeks help and the intervention of an institution. Only roughly 20\% of women who have experienced more threatening kinds of violence find their way to psychosocial aid institutions. Even fewer cases are reported to the police (Schröttle and Müller 2005). It is therefore interesting to find out more about why the aid provided by the European care system reaches so few women who are affected by violence.

\section{'I always know when he has been there' - a case example}

While some significant changes have been achieved for women who are victims of violence in approximately 30 years of anti-violence work, we are still light years away from having solved the problem of gender-based violence (Heise, Ellsberg and Gottemoeller 1999). Whereas support services do improve the lives of many abused and raped women, they have almost 
no influence on the fact that men perpetrate the violence. Moreover, a substantial number of women return to their abusive relationships, despite having made contact with the help system once or several times. Thus, one of the factors that need to be considered in the attempt to provide sustainable help is the issue of 'safety'. Consider the following example:

I am tired. I have just come back from the police station. I had to fill out the forms to extend the restriction order against my ex-husband, again. He will never leave me alone. I wonder if the police think it is my fault?

Today, my home has become my refuge, after I left the women's refuge nine months ago. I want to move on with my life and the lives of my children. Sometimes I wish Margareta was here to support me as I decide what to do next. She was always there when I needed someone to talk to at the refuge. She knew when I was crying silently in my room. The children felt safe at the refuge and they enjoyed going out with the other children. I could stay behind and have time for myself. That was really helpful. Maybe I will call her.

He was at our back window again. I always know when he has been there. Yesterday the children said he sometimes shows up at school. I should have known. He has complained to the child welfare department that he wants to see his children. I think he just wants to get to me. It isn't about them. The woman at the welfare office says that a father has the right to see his children. I guess he went to anger management courses. What can I do?

If we have to go to court again, I hope we have the same judge as last time. She really put him in his place. He tried to lie to her and she did not believe him. That was good. The police told me to stay in touch with my attorney. I will make another appointment. She knows me. She knows the law.

Does anyone know him?

I suppose there are men who say, 'All right, then I'll stop it', or who give up at some point. And there are men like mine who don't stop. At some point you just have to hope.

This example shows how much and how constantly a woman can worry about whether she is actually protected from further violence. Victims report that factors that influence this feeling of overall safety are their relationships with the person responsible for them at the women's refuge and an increasing confidence in the judge to which their case has been assigned. However, even under these quite positive circumstances they remain constantly preoccupied with the violence that their former partner continues to perpetrate and the power that he still exerts. Because they 
cannot cope with this inner pressure in the long term, many women finally decide to go back to their previous living arrangements and to put up with the violence iso as to avoid being exposed to constant psychological terror. Why do the women not manage to continue following their own paths with the support of the help system? Why do they become paralysed when they meet their former partners again and unable to distance themselves from them even in public, where the perpetrators' hands are tied? Why do such clear situations of 'learned helplessness' (Seligman 1972) that lead many women to give up, occur? To find this out we need to take a brief look at the dynamics of the sequelae of violence.

\section{Supporting women not to give up. The importance of safety in anti- violence work}

In the majority of cases domestic violence results in traumatic stress. But what is a trauma? The concept is not easy to capture. Fischer and Riedesser (1998: 79) define trauma as an experience of a 'vital discrepancy between threatening factors of a situation and individual coping capacities' which goes far beyond the limits of an individual's ability to confront it. As a rule, trauma is associated with the experience of powerlessness and loss of control, horror and fear (of death). Traumatic experiences can lead to a traumatic reaction. The symptoms begin with what is called an acute stress reaction. Post-traumatic stress disorder is not diagnosed until the symptoms have persisted for longer than four weeks. From a duration of three months onwards the disorder is considered to be chronic (DSM-IV). If the impairment continues for several years or decades, the post-traumatic stress can develop into an enduring personality change following catastrophic stress (ICD-10).

The extent of the traumatisation is dependent on the nature, circumstances and duration of the event, the developmental status of the victim at the time of traumatisation and other factors that may be present or the absence of protective factors. Forms of persistent and repeated traumatisation in intimate relationships lead to phenomena of severe psychological fragmentation and disintegration, which profoundly disrupts the person's feeling of safety and security in the world and the confidence in 
humanity which develops in a child's first attachment relationships. JanoffBulman (1985) describes this phenomenon as 'shattered assumptions' - a fundamental shaking of basic convictions such as positive perceptions of the self, expectations of the world and the feeling of safety and security in it and trust in interpersonal interactions (see also Sachsse 2006).

This makes the statements made by the women in the interviews, which contain repeated references to the absence of a feeling of safety, more readily understandable. Their experience of their current situations is coloured by 'fear structures' that have previously been 'etched into' the neurophysiology of their brains (Siegel 1972). In such situations of threat, traumatised women perceive cues and dangers quite differently and classify them differently from people who have not been traumatised. In addition to the current stress, the danger of the present situation also reactivates the memories of many prior experiences and surrounds the victim with a whole series of previous acute traumatic situations in which she was afraid of being killed and experienced absolute powerlessness. The woman becomes paralysed and feels that she cannot and never will be able to do anything to stop what is happening. Her entire psychophysiological system is overtaxed. 'Nobody supported me', a respondent said in one of the interviews, '... not my family, nobody. Nobody. No-one at all. I was really afraid that he would come home and do the same thing again".

The traumatic stress includes not only the trauma itself, but also the events that are linked with it later on, e.g. in the course of psychosocial interventions. Women who have been in extreme situations remain caught up in them until they receive help in a concrete form. Until that point they are often as if paralysed. 'If I see his car in the rear-view mirror, I'm scared. If I see an email in my inbox, I'm scared. I'm always scared, I am, because he's always creeping around somewhere and watching me'. As providers of help we therefore have a chance - if only a small one - of being able to intervene supportively. The question thus arises as to how psychosocial support services can help women who fall victim to violence to come to terms with their terrifying experiences and once more to react in a different way to external stimuli and dangers. Professional helpers have collaborated internationally to develop treatment models that focus anew on the significance of safety as a dimension of positive coping (for example, 
Butollo, Krüsmann and Hagl 1998; Lebowitz, Harvey and Herman 1993; Wintersperger 2006).

Thus, one of the main prerequisites for successful processing of traumatic violence is the provision of a minimum of safety. Once this has been ensured, the work needs to begin with stabilisation and accessing of resources before the victim can progress to reconstructing her shattered capacity for gaining control of the situation. An important part of this is accessing social resources and also establishing a substantial amount of legal and public safety. However, legal and 'public' safety also play no small a part. Only then can the victim begin to come to terms with the violence to which she has been subjected. By integrating what she finds impossible to accept and overcoming the fears associated with it she can gradually begin to approach her environment again. Under new circumstances it is then possible for her to focus on the opportunities available to her in her current life.

Research on psychotherapy and counselling has also demonstrated how strongly the success of professional interventions is affected by skilled work on attachments and relationships and by integration into networks that provide security in the social sphere (see for example Grawe 2004; Orlinsky, Grawe and Parks 1994; Nestmann 1988). Ensuring that professional helpers are familiar with the phenomena of attachment, social support and possible disorders and traumas enables them to address these aspects satisfactorily. However, a professional approach to working with the helping relationship is only part of the complex security system that needs to be provided for these women. If there are problems with the legal system or the social environment it is not possible to ensure that the women enjoy adequate safety, even with the help of highly qualified support workers.

Thus optimally, safety for women who are victims of violence should be assured on different levels:

- on the everyday level by establishing a safe milieu in the supporting institution - usually a women's refuge;

- on the level of the professional helping relationship tby providing a committed, personal and reliable relationship with the member of the psychosocial staff responsible for the client;

- on the systems level by networking with other institutions; 
- on the legislative level by ensuring that the legal system meets the requirements of victims;

- and on the social level by ensuring that treatment of victims of violence is respectful and neither stigmatising nor trivialising.

Only if safety is ensured on all these levels can victims succeed in escaping from the system of violence.

\section{Conclusions}

In Europe great value is placed on human rights and thus also on the rights of women both on the level of the law and in public perception (Council of Europe Parliamentary Assembly 2009; United Nations 2010). Both policymakers and service providers stress the central importance of integrity and safety for women who fall victim to violence. However, like previous research (Schröttle and Müller 2005), the results of the present study show that there is still a large gap between the apparent progress made in the legislative and sociopolitical spheres and women's concrete chances of obtaining effective protection and claiming their rights without having to overcome substantial hurdles. One aim of this study was therefore compare these findings with the current legislation, policy and practices within partner communities.

The results of the study reveal that these domains are influenced by various different factors. Thus they show that good practice requires a network of professionals trained in psychosocial work and comprehensive services that meet the crucial safety needs and do justice to the complexity of trauma dynamics. At the same time they must implement a multiprofessional approach that is firmly anchored in human rights and diversity values as a wider frame for interventions.

However, the most important result of the research of the past 30 years has been the persistent finding that women who have experienced violence require comprehensive safety and active support from the help system. The importance of believing help-seeking women unconditionally (Tucker 2010), of ensuring that they have access to safety promptly and receive skilled specialised psychosocial support provided by qualified professionals cannot be strongly enough stressed. This requires programmes that are more 
complex than initially assumed. Police actions at the scene must be suitably informed. Psychosocial support must also include advice on the relevant legal issues and/or put victims in contact with legal advice services. The provision of comprehensive support services by a single professional remains the most important component and is key for success.

Programmes based on the systemic approach play an important role. The formation of networks that stretch beyond the individual helpproviding institution must be a core component of schemes implemented by help providers in the anti-violence system (BMFSFJ and BMJ 2010). The main focus must be on the woman's family systems as a whole, including the children (Community Care 2008). Many victims of violence concentrate their efforts on their childrren. If (for structural reasons) children cannot be offered conditions that are conducive to healthy development, many women will do without support for themselves, even if in the long term this decision sometimes proves to have been ill-advised. In this context, restraining orders forbidding the (alleged) abuser to come within a certain distance of the victim are important. Particular attention should therefore be paid to this legal instrument.

The interview evidence gathered supports the view that victims of domestic violence have complex and multi-layered needs. These can be immediate needs (for access to information/options, space to assess the situation and make rational decisions, someone to act as counsellor/advisor, immediate access to a secure situation) and long term needs (for advocacy, legal representation, financial advice/public aid, social work support, support for developing new personal and family goals, appropriate accommodation to move into). However, respondents acknowledged that community-based services need to be built on simple structures that offer the opportunity to access agencies with limited bureaucratic requirements.

The results of this study show that on the structural level there are still insufficient funds to guarantee that the measures in place will function smoothly. For instance, services for women who are victims of violence who live in rural areas are still rare in all countries. In all cases the reimbursement system must also be structured in such a way that women who are in the process of extricating themselves from a violent family situation do not suffer from increased financial pressure. The results of the project also show 
that victims would like to have a help system in which the truth of their reports is not constantiy doubted. While providing them with accommodation with other women helps to develop a feeling of solidarity, if due to lack of funds refuges have no rooms to which they can withdraw this feeling can be reversed, with negative effects.

In order to respond to such a wide range of problems, victim support services need to be highly sensitised to the needs of potential service users. Ultimately, this means developing programmes that offer support and encouragement for each individual woman to achieve change within the context of her personal environment and life circumstances and to be equipped to face situations fraught with multiple problems (Pauls 2004; Pauls 2011). Care for women who are victims of violence could be improved if light could be thrown on the interfaces between mental, social, physical aspects and everyday situations, so as to be able to really reach the women and offer them sufficient safety. However, if this is to be achieved, countries also need to provide adequate financial, staffing and structural resources and a social environment that is free of lingering taboos and structures of denial and manages to improve co-ordination between the different reference systems in which the women must move. The necessary supports must be adjusted to the women's specific individual life situations in such a way that they appear to come 'from a single source' (Freese, Holz and Adam 2009: 6).

Daphne has had an important indirect impact on the development of policies and legislation addressing violence towards women and children. Its overall aim is to promote the idea of a common European normative basis for dealing with violence against women and children; one that can be developed with the recommendations of the EU by means of transnational action. This basis can be channeled into national policies and to NGOs, the main partners in Daphne (Montoya 2008: 361). Daphne also facilitates transnational networking among these organizations. Many observers have noted the importance of transnational women's networks for the development of policy responses and good practice models to address violence against women and children (Krizsan and Popa undated).Through the adoption of an advocacy approach, the research project described in this article was designed to proactively promote the voices of service users in 
order to gain a clearer understanding of their needs and expectations of victim support services. The project hopes that the voices of the victims can help to develop a more effective policy and practice and to diminish the stigmatisation and stereotyping of victims of domestic violence and their family members.

\section{Acknowledgements}

The paper was partially supported through the EU program Daphne III, grant number: JLS/2007/ DAP-1/058 30-CE-0227730/00-44, project title: 'A Comparative Analysis of Community Focused Initiatives Aimed at Supporting Women, Children and Young People Who Have Been the Focus of Violence, Exploitation or Trafficking in three regions of the United Kingdom, Germany and Romania'.

\section{References:}

Bundesministerium für Familie, Senioren, Frauen und Jugend (BMFSFJ) and Bundesministerium der Justiz (BMJ). 2010. Mehr Schutz bei häuslicher Gewalt. Informationen zum Gewaltschutzgesetz. http:/ / www.big-koordinierung.de/veroeffentlichungen/ broschueren/pdfs/1012_Mehr_Schutz.pdf (accessed May 26, 2011).

Butollo, Willi, Marion Krüsmann and Maria Hagl. 1998. Leben nach dem Trauma. Über therapeutischen Umgang mit dem Entsetzen. München: Pfeiffer.

Community Care. 2008. Proven practice - Impact of domestic violence on children.

http:/ / www.ccinform.co.uk/Articles/2008/07/10/2667/Impact+of +domestic+violence+on+children.html (accessed May 26, 2011).

Council of Europe Parliamentary Assembly. 2000. Recommendation 1450 (2000). Violence against women in Europe. Council of Europe. http:/ / assembly.coe.int/Main.asp?link=/Documents/AdoptedText /ta00/EREC1450.htm (accessed December 10, 2009).

Felitti, Vincent J. 2002. Belastungen in der Kindheit und Gesundheit im Erwachsenenalter. Die Verwandlung von Gold in Blei. Zeitschrift für Psychosomatische Medizin und Psychotherapie 48 (4): 359-369.

Fischer, Gottfried and Peter Riedesser. 1998. Lehrbuch der Psychotraumatologie. München: Reinhardt.

Freese, Werner, Michael Holz and Signe Adam. 2009. Kooperation von Kinderund Jugendpsychiatrie, Jugendhilfe und Schule in der Region Berlin Südwest. Abschlussbericht des Modellprojekts. Berlin: Bezirksamt Tempelhof-Schöneberg. 
Gahleitner, Silke Birgitta. 2007. Gewalt und Geschlechterverhältnis aus weiblicher Sicht. In Gewalt und Geschlechterverhältnis. Interdisziplinäre und geschlechtersensible Analysen und Perspektiven, eds. Silke Birgitta Gahleitner and Hans-Joachim Lenz, 53-70. München: Juventa.

Grawe, Klaus. 2004. Neuropsychotherapie. Göttingen: Hogrefe.

Harvey, Alison, Claudia Garcia-Moreno and Alexander Butchart. 2007. Primary prevention of intimate-partner violence and sexual violence: Background paper for WHO expert meeting May 2-3, 2007. World Health Organization.

http://www.who.int/violence_injury_prevention/publications/viol ence/IPV-SV.pdf (accessed May 26, 2011).

Heise, Lori, Mary Ellsberg and Megan Gottemoeller. 1999. Ending violence against women. Center for Communication Programs.

http://info.k4health.org/pr/111/violence.pdf (accessed May 26, 2011).

Janoff-Bulman, Ronnie. 1985. The aftermath of victimization: Rebuilding shattered assumptions. In Trauma and its wake. The study and treatment of post-traumatic stress disorder, ed. Charles R. Figley, 15-35. New York: Brunner/Mazel.

Kavemann, Barbara. 2001. Entwicklung der Diskussion über Gewalt im Geschlechterverhältnis. Historische Verschiebungen, neue Schwerpunkte, neue Verknüpfungen. Vortrag beim Hochschultag der ASFH Berlin am 31.10.2001 'Frauen in Gewaltverhältnissen'. http:/ / www.wibig.uni-osnabrueck.de/download/ASFH.doc (accessed April 11, 2009).

Krizsán, Andrea, and Raluca Popa. Undated. Stretching EU conditionality: Mechanisms of europeanization in making domestic violence policies in Central and Eastern Europe.

http:/ / www.quing.eu/files/2009/krizsan_popa_europeanization_s ubmit.doc (accessed December 11, 2009).

Lebowitz Leslie, Mary R. Harvey and Judith L. Herman. 1993. A stage-bydimension model of recovery from sexual trauma. Journal of Interpersonal Violence 8 (3): 378-391.

Montoya, Celeste. 2008. The European Union, capacity building, and transnational networks: Combating violence against women through the Daphne Program. International Organization 62 (2): 359-372.

Nestmann, Frank. 1988. Die alltäglichen Helfer. Berlin: de Gruyter.

Orlinsky, David E., Klaus Grawe and Barbara K.Parks 1994. Process and outcome in psychotherapy. In Handbook of psychotherapy and behavior change, 4th ed., eds. Allen E. Bergin and Sol Louis Garfield, 270-376. New York: Wiley.

Pauls, Helmut. 2011. Klinische Sozialarbeit. Grundlagen und Methoden psychosozialer Behandlung. München: Juventa. 
Pauls, Helmut. 2004. Klinische Sozialarbeit. Grundlagen und Methoden psychosozialer Behandlung. Weinheim: Reinhardt.

Rutz, Wolfgang. 2006. Mental health promotion in times of transition. Klinische Sozialarbei 2 (1): 4-5.

Sachsse, Ulrich. 2006. Beziehung als Trauma: der nicht sexuelle Missbrauch. Persönlichkeitsstörungen - Theorie und Therapie 10 (2): 99-104.

Schröttle, Monika and Ursula Müller. 2005. Lebenssituation, Sicherheit und Gesundheit von Frauen in Deutschland. Ergebnisse der ersten bundesweiten Prävalenzstudie zu Gewalt gegen Frauen. In Gewalt im Leben von Männern und Frauen. Forschungszugänge, Prävalenz, Folgen, Intervention. Kongressbericht, 21-37. Bundesministerium für Familie, Senioren, Frauen und Jugend (BMFSFJ).

Seligman, Martin E. P. 1972. Learned helplessness. Annual Review of Medicine, 23: 407-412.

Tucker, Stanley. 2010. Listening and believing: An examination of young people's perceptions of why they are not believed by professionals when they report abuse and neglect. Children $\mathcal{E}$ Society 25 (3): 1-12.

United Nations. 2010. Intensification of efforts to eliminate all forms of violence against women.

http://daccess-dds-ny.un.org/doc/UNDOC/GEN/N10/470/41/ PDF/N1047041.pdf (accessed May 26, 2011).

World Health Organisation. 1996. Violence against women. http://whqlibdoc.who.int/hq/1996/FRH_WHD_96.27.pdf (accessed March 12, 2011).

Wintersperger, Sylvia. 2006. Wann ist das Trauma zu Ende? Wege und Ziele in der Traumatherapie. Imagination 28 (2): 39-48. 